\title{
Emission characteristics of volatile organic compounds released from spray products
}

\author{
Hyo-Jae Jo, Bo-Won Kim, Yong-Hyun Kim, Min-Hee Lee, Sang-Hee Jo, Ki-Hyun Kim ${ }^{\star}$, \\ Joon-Young Kim ${ }^{1}$, Jun-Ho Park ${ }^{1}$, Soo-Min Oh${ }^{1}$, Seung-Hwan Lee ${ }^{1}$ and Dong-Yeon Kim ${ }^{1}$ \\ Department of Environment \& Energy, Sejong University, Seoul 143-747, Korea \\ ${ }^{1}$ Ban-po high school, Seoul 137-041, Korea
}

(Received December 28, 2013; Revised June 21, 2013; Accepted June 21, 2013)

\section{생활 스프레이 제품의 안전성 조사: 벤젠과 톨루엔 함량을 중심으로}

\author{
조효재 · 김보원 · 김용현 · 이민희 · 조상희 · 김기현` · 김준영 ${ }^{1}$ - 박준호 ${ }^{1}$ • \\ 오수민 ${ }^{1} \cdot$ 이승환 $^{1} \cdot$ 김동연 $^{1}$ \\ 세종대학교 환경에너지융합학과, ${ }^{1}$ 반포고등학교 \\ (2013. 12. 28. 접수, 2013. 6. 21. 수정, 2013. 6. 21. 승인)
}

\begin{abstract}
Many kinds of liquid spray products are used in livelihood activities these days. Spray products can be distinguished by the target to be sprayed (like into the air or on human skin (body)). Because human can be exposed to volatile organic compounds (VOC) emitted from spray products, some considerations on safety or hazard of spray products should be needed. In this study, emission characteristics of VOCs were investigated against 10 types of liquid spray products (6 skin spray and 4 air spray products). The concentrations of benzene and toluene were determined by gas chromatography/mass spectrometry (GC/MS) equipped with a thermal desorber (TD). Their average concentrations from 6 skin spray products exhibited $5.64 \pm 1.95$ (mean \pm S.D) and $8.52 \pm 2.89 \mathrm{ppb}(\mathrm{w})$, respectively. In contrast, those of 4 air spray samples had $7.30 \pm 1.31$ and $7.19 \pm 1.78 \mathrm{ppb}(\mathrm{w})$, respectively. If liquid contents in spray samples are completely vaporized in one cubic meter $\left(1 \mathrm{~m}^{3}\right)$ after spraying for 10 seconds, their mean concentrations of skin spray products are $31.7 \pm 8.80$ (benzene) and $50.5 \pm 17.1 \mu \mathrm{g} /$ $\mathrm{Sm}^{3}$ (toluene). In contrast, those of air spray products are $24.0 \pm 4.30$ (benzene) and $23.6 \pm 5.83 \mu \mathrm{g} / \mathrm{Sm}^{3}$ (toluene). The estimated concentration levels of benzene from two types of products $\left(31.7\right.$ and $24.0 \mu \mathrm{g} / \mathrm{Sm}^{3}$ ) exceeded the Korean atmospheric environmental guideline $\left(5 \mu \mathrm{g} / \mathrm{Sm}^{3}\right)$. The results of this study thus suggest that some measures should be made to reduce or suppress the contents of VOC in spray products.
\end{abstract}

요 약: 최근 생활 스프레이 제품들의 사용이 증가하고 있다. 스프레이 제품은 크게 공기중으로 분사하 거나 인체에 직접 분사하는 제품으로 나눌 수 있다. 스프레이 제품 내 존재하는 물질들은 분사함과 동시 에 인체에 흡입 및 피부에 노출되기 때문에, 물질에 대한 안전성 평가가 필요하다. 본 연구에서는 생활 환경에서 주로 사용하는 10 가지 종류의 스프레이 제품 내 발암물질로 잘 알려진 벤젠과 인체 악영향을 줄 수 있는 톨루엔의 함량을 조사하였다. 조사 결과, 10 가지 제품에서 모두 벤젠과 톨루엔을 검출하였

$\star$ Corresponding author

Phone : +82-(0)2-3408-323 Fax : +82-(0)2-3408-4320

E-mail : khkim@sejong.ac.kr 
다. 피부에 분사하는 6 종의 제품에서 벤젠은 평균 $5.64 \pm 1.95 \mathrm{ppb}(\mathrm{w})$, 톨루엔은 평균 $8.52 \pm 2.89 \mathrm{ppb}(\mathrm{w})$ 농 도수준으로 검출하였다. 공기중으로 분사하는 4종의 제품에서는 벤젠과 톨루엔이 각각 $7.30 \pm 1.31 \mathrm{ppb}(\mathrm{w})$, $7.19 \pm 1.78 \mathrm{ppb}(\mathrm{w})$ 농도로 검출하였다. 이들을 10 초간 1 입방미터에 분사하여 완전 기화한다고 가정할 경 우, 6 종의 제품에서 벤젠은 평균 $31.7 \pm 8.80 \mu \mathrm{g} / \mathrm{Sm}^{3}$, 톨루엔은 평균 $50.5 \pm 17.1 \mu \mathrm{g} / \mathrm{Sm}^{3}$ 농도수준으로 검 출하였다. 공기 중으로 분사하는 4 종의 제품에서는 벤젠과 톨루엔이 각각 $24.0 \pm 4.30 \mu \mathrm{g} / \mathrm{Sm}^{3}, 23.6 \pm 5.83$ $\mu \mathrm{g} / \mathrm{Sm}^{3}$ 농도로 검출하였다. 10 가지 스프레이제품에서 발생한 벤젠의 경우, 우리나라 대기환경 기준치인 $5 \mu \mathrm{g} / \mathrm{Sm}^{3}$ 을 초과한 수치에 해당한다. 생활환경 내 스프레이제품의 사용에 주의가 요구된다.

Key words: Volatile organic compounds (VOC), benzene, toluene, spray product, GC/MS

\section{1. 서 론}

과학의 발전으로 사람들의 생활수준이 나아지자 사 람들은 식량 문제나 수질 오염의 문제들을 우려하던 차원에서 청결한 생활에 대한 관심으로 옮겨지고 있 는 추세를 보이고 있다. 그 결과, 청결한 생활을 위해 사람의 생활 속에 존재하는 유해물질들의 종류와 성질 에 관한 다양한 연구들이 활발하게 수행되고 있다.1,2 이런 유해물질들 중 가장 대표적인 예로 $\mathrm{VOC}$ 를 들 수 있다. $\mathrm{VOC}$ 는 증기압이 높아 대기 중으로 쉽게 증 발하는 액체 또는 기체상의 탄화수소화합물을 총칭하 는데 이들은 대체로 휘발성이 높고 꼻는점이 낮아 휘 발성이 강해 악취나 오존을 발생시키는 성질이 있다. $\mathrm{VOC}$ 는 마비성이 강해 피부 접촉이나 호흡기로의 흡 입 등을 통해 인체의 신경계에 손상을 입힌다. 또한 일부 물질들은 오존 및 2 차 오염물질들을 생성하고, 광화학 산화반응으로 인해 스모그를 생성하기도 한다. ${ }^{3}$ $\mathrm{VOC}$ 의 대표적인 예로 벤젠(Benzene)과 톨루엔(Toluene) 을 들 수 있다. 벤젠은 대표적인 1급 발암 물질로, 현 재 활발한 연구가 진행되고 있는 $\mathrm{VOC}$ 이다. 벤젠의 배출원은 담배연기, 자동차 배기가스, 공장의 굴뚝, 각 종 유기용제 및 실내 건축자재 등으로 알려져 있다. ${ }^{4}$ 특히 담배연기의 경우, $150 \sim 204 \mathrm{mg} / \mathrm{m}^{3}$ 의 고농도 벤 젠을 함유하고 있어서 최근 환경대기 중으로 배출하 는 심각한 벤젠의 발생원으로 주목 받고 있다. 톨루엔 은 톨루올(toluol), 메칠벤젠(menthyl benzene)이라고도 불리며, 주로 호흡기를 통해 체내로 흡수되어 눈, 호 흡기, 피부 등의 점막 자극 증상과 중추신경에 대한 증상 등을 유발하는 독성 물질이다. 톨루엔도 벤젠과 마찬가지로 사람의 생활 환경에서 많은 양이 배출된 다. ${ }^{5}$ 현대에 이르러 사람들의 생활수준을 크게 향상시 켜 준 편리하고 간단한 생활용품들이 많이 등장하였 지만, 이런 용품들은 어떠한 종류의 $\mathrm{VOC}$ 를 포함하고
있고 그 것이 인체에 어떤 영향을 미치는가에 대한 체계적인 정보가 부족하다. 이들의 존재에 대한 파악 여부는 인체를 좌지우지할 수 있는 정도이기에 사람 들에게 크게 요구된다. 따라서 이러한 생활용품들을 중심으로 $\mathrm{VOC}$ 의 배출특성을 체계적으로 정리하기 위 한 연구가 필요하다.

본 연구에서는 가스크로마토그래프(Gas chromatograph, $\mathrm{GC}$ )와 질량분석기(Mass spectrometer, MS)를 결합한 시스템을 이용하여, $\mathrm{VOC}$ 성분 중 벤젠과 톨루 엔을 중점적으로 분석하였다. ${ }^{6}$ 그리고, 이를 위해 분석 대상을 대기 중에 분사하는 스프레이 제품으로 제한 하였다. 분석 대상 시료로는 피부에 직접 뿌리는 용도 로 에어파스, 데오드란트, 살충제 2 종, 헤어스프레이, 미스트를 준비하였고 공기 중에 뿌리는 용도로는 살 충제 2 종, 향균스프레이, 방향제를 준비하였다. 이들 시료들은 용기에 액상 상태로 분취하여, 일정량을 고 체흡착관에 흡착시키는 방식으로 채취하였다. 그 후, 저온농축열탈착시스템(Thermal desorber; TD)을 연계 한 GC/MS (Gas chromatography/mass spectrometry)를 이용하여 벤젠과 톨루엔의 정성 및 정량분석을 시도 했다. 이러한 분석 결과를 바탕으로 대표적인 $\mathrm{VOC}$ 인 벤젠과 톨루엔을 조사함으로써, 생활 분무제품의 잠정 적인, 혹은 돌발적인 유해성을 간접적으로 평가하고자 하였다.

\section{2. 연구방법}

\section{1. 분석 시스템 구성}

본 연구에서는 저농도 수준의 휘발성 유기화합물을 고감도로 분석하기 위하여, 저온 농축 열탈착시스템 (Thermal desorption; TD, Unity, Markes International, Ltd, UK)을 연계한 GC (Gas chromatography, Shimadzu GC-2010, Japan)/MS (Mass spectrometry, model Shimadzu 
Table 1. A list of target compounds and their basic information

\begin{tabular}{ccccccc}
\hline \hline & Compounds & Acronym & Formula & $\mathrm{MW}(\mathrm{g} / \mathrm{mol})$ & $\mathrm{CAS}$ number & Structural \\
\hline \multirow{2}{*}{ Aromatic VOCs } & Benzene & $\mathrm{B}$ & $\mathrm{C}_{6} \mathrm{H}_{6}$ & 78.1 & $71-43-2$ \\
& Toluene & $\mathrm{T}$ & $\mathrm{C}_{7} \mathrm{H}_{8}$ & 92.1 & $108-88-3$ \\
\hline
\end{tabular}

GCMS-QP2010, Japan)를 활용하였다. 본 시스템의 적 용은 대기 중 극단적으로 낮은 $\mathrm{ppb}$ 또는 그 이하의 농도로 존재하는 시료의 분석에 적합하다. 따라서 역 설적으로 열탈착 시스템을 장착하면, 고농도 시료의 직접 주입이 불가능하다. 따라서 고농도의 시료와 저 농도의 시료의 분석에 동시 적용을 하기 위해서는 여 러 가지 시스템의 변형 운용이 필요하다.

TD system 내부의 저온농축관(cold trap)은 Carbopack $\mathrm{B}$ 와 Tenax TA를 1:1의 부피 비로 혼합하여 사용하였 다. 3 가지 종류의 흡착제(Tenax TA, Carbopack B, Carboxene 1000)를 각각 $100 \mathrm{mg}$ 씩 충진한 고체흡착 관을 이용하여 시료를 흡착하고, TD system을 이용 하여 고온에서 열탈착을 유도하였다. 스프레이 시료 내 조사대상 benzene과 toluene (Table 1)은 CP-Wax column (diameter: $0.25 \mathrm{~mm}$, length: $60 \mathrm{~m}$, film thickness: $0.25 \mu \mathrm{m})$ 을 통해, 매회 20 분의 주기로 설정하여 분 리 · 분석하였다(Table 2).

\section{2. 분석방법}

분석대상 시료와 표준시료는 액상형태로 준비하였 으며, 고체흡착관을 기반한 TD-GC-MS system으로 분석하였다. 최초, back-up gas (ultra-pure nitrogen > 99.999\%)로 채운 $10 \mathrm{~L}$ polyester aluminum (PEA) bag 을 고체흡착관의 전단부와 연결하였다. 이 때, 고체 흡착관의 후단부는 다시 mass flow controller (MFC) 를 장착한 vacuum pump와 연결하였다. 고체흡착관의 연결부는 모두 teflon tube를 사용하였다. 액상표준시 료를 고체흡착관 방식으로 분석하기 위해 이들을 주 입하기 위한 시료 주입구를 PEA bag과 고체흡착관 의 전단부를 연결한 teflon tube에 임시로 만들었다. Vacuum pump를 이용하여 back-up gas를 고체흡착 관으로 흘려주는 상태에서 액상 시료를 임시 시료 주입구를 통해 주사하였다. Back-up gas는 $100 \mathrm{~mL}$ $\mathrm{min}^{-1}$ 으로 5 분간 흘려줌으로써, 고체흡착관에 시료 를 주입하는 과정에서 오염의 발생을 방지하고자 하 였다.

\section{3. 작업용 표준시료 조제}

본 연구에서는 대기 중에 분사하는 제품에 포함한 benzene과 toluene의 정량분석을 위해 표준물질을 이 용하여 검량선을 확보하였다(Table 3). 표준물질을 조 제하기 위하여, $99.5 \%$ 수준의 benzene 및 toluene의 원표준시료 (Primary Standard; PS, Sigma-aldrich, USA)를 희석하는 방식으로 4 가지 농도의 표준시료 를 조제하였다. 먼저, 1 차 작업용 표준시료(1st working standard: $1 \mathrm{st} \mathrm{WS}$ )를 조제하기 위하여, $20 \mathrm{~mL}$ vial에 methanol (100\%, Burdick \& Jackson, USA) $19.4 \mathrm{~mL}$ 와 benzene 및 toluene의 PS를 각각 $0.3 \mathrm{~mL}$ 씩 혼합하 여, 최종 농도를 $13,104 \mathrm{ng} / \mu \mathrm{L}$ 로 조제하였다. 2 차 작 업용 표준시료(2nd working standard: 2nd WS)는 1차 작업용 표준시료를 메탄올을 이용하여 100 배 희석하 는 방식으로 $131 \mathrm{ng} / \mu \mathrm{L}$ 수준으로 조제하였다. 최종 작업용 표준시료(Final working standard: F-WS)는 1.5

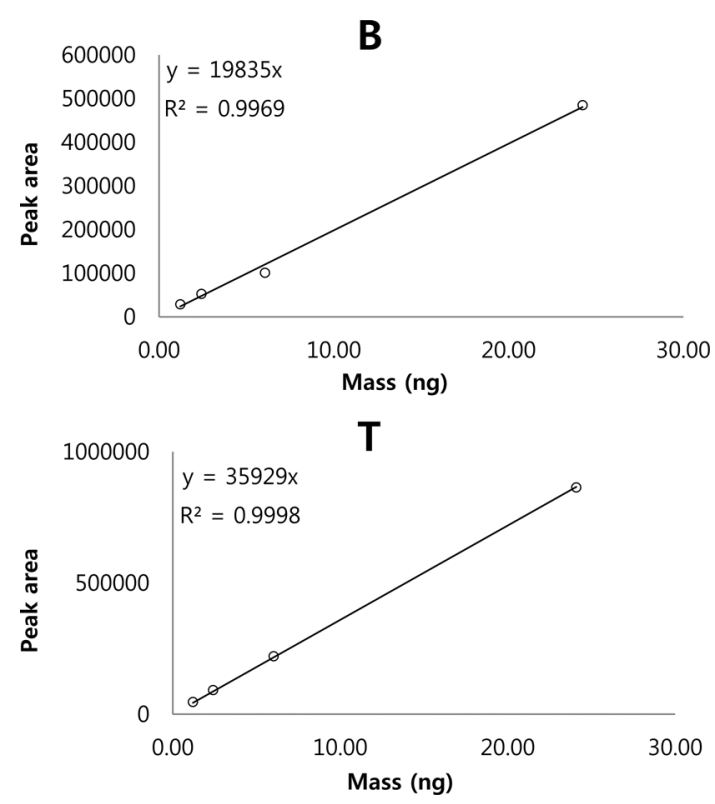

Fig. 1. Calibration results of target VOC derived by standard. 
$\mathrm{mL}$ vial에 methanol을 이용하여 2 차 작업용 표준시 료를 희석하는 방식으로 4 가지 농도( $1.31,2.62,6.55$, $13.1 \mathrm{ng} / \mu \mathrm{L}$ )로 조제하여 검량선을 도출하였다(Fig. 1). 또한, $\mathrm{QA} / \mathrm{QC}$ 차원에서 재현성 $(\mathrm{RSE}(\%))$ 과 검출한계 (ppb)값을 도출하였다(Table 3).

\section{4. 시료의 준비}

분석대상 시료로는 에어파스, 데오도란트, 살충제 4 종, 헤어 스프레이, 미스트, 향균 스프레이, 방향제를 준비하였다(Table 4). 분석대상 시료인 분무제품 내 benzene, toluene 성분들의 정량분석을 위해, 본 연구 에서는 준비한 원 분석대상 시료들을 각각 $20 \mathrm{~mL}$ vial에 분사하여, 액상형태로 채취하였다. 액상 형태의 분석대상 시료들은 methanol $(>100.00 \%$, Burdick \& Jackson, USA)을 gravimetric 방식으로 100 배 희석하 여 분석하였다. 이와 같은 방식으로 준비한 시료들을 3 가지 종류의 흡착제(Tenax TA, Carbopack B, Carboxen $1000)$ 를 각각 $100 \mathrm{mg}$ 씩 충진한 고체흡착관을 이용하 여 흡착하였다. 고체흡착관 전단부에는 고순도 질소 (99.999\%) 가스를 채운 $10 \mathrm{~L}$ polyester aluminum (PEA) $\mathrm{bag}$ 을 연결해 주었다. 이와 동시에, 후단부에는 mass flow controller (MFC)를 장착한 미니펌프(SIBATA MP$\Sigma 30)$ 를 연결하였다. 고체흡착관의 연결부는 모두 Teflon tube를 사용하여, 흡착반응을 최소화하고자 하
였다. 분석 대상 시료를 고체흡착관에 주입하기 위하 여, PEA bag과 고체흡착관의 전단부를 연결한 Teflon tube에 주사기를 관통하여 주사하였다. 이 때, back-up $\operatorname{gas}\left(\mathrm{N}_{2}\right)$ 는 앞서 표준시료를 고체흡착관에 주입할 때 와 같이 를 $100 \mathrm{~mL} / \mathrm{min}$ 으로 5 분간 총 $500 \mathrm{~mL}$ 만큼 고체흡착관으로 흘려주었다. 스프레이 시료의 분석결 과로 확보한 크로마토그램은 Fig. 2에 제시하였다.

\section{5. 고체흡착관 분석의 의의}

본 연구에서는 메탄올을 용매로 만든 액상 표준시

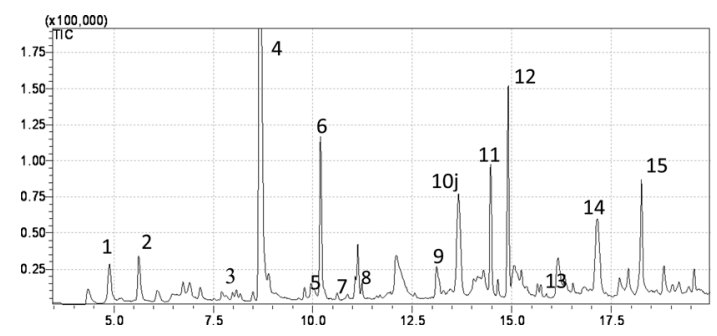

Fig. 2. Chromatogram of VOC in actual samples (code: SL-4 (refer to Table 3)) by TD-GC-MS method: (1) propane, (2) methyl formate, (3) MEK, (4) ethyl alcohol, (5) benzene, (6) methyl butanoate, (7) methyl methacrylate, (8) toluene, (9) n-octanal, (10) ethyl acetoacetate ethylene acetal, (11) dlLimonene, (12) eucalyptol, (13) Stsrene, (14) benzyltert-butanol, and (15) linalool tetrahydride.

Table 2. Operational condition of $\mathrm{TD}^{\mathrm{a}}$-GC-MS system for the analysis of target VOC

\begin{tabular}{|c|c|c|c|}
\hline \multicolumn{4}{|c|}{ GC (SHIMADZU GC-2010, JAPAN), MS (SHIMADZU GCMS-QP2010, JAPAN) } \\
\hline \multicolumn{4}{|c|}{ Column: CP Wax (diameter: $0.25 \mathrm{~mm}$, length: $60 \mathrm{~m}$, and film thickness: $0.25 \mu \mathrm{m}$ ) } \\
\hline \multicolumn{2}{|r|}{ Oven setting } & \multicolumn{2}{|c|}{ Detector setting } \\
\hline Oven temp: & $40^{\circ} \mathrm{C}(4 \mathrm{~min})$ & Ionization mode: & EI $(70 \mathrm{eV})$ \\
\hline Oven rate: & $10{ }^{\circ} \mathrm{C} \min ^{-1}$ & Ion source temp.: & $200{ }^{\circ} \mathrm{C}$ \\
\hline Max oven temp: & $200{ }^{\circ} \mathrm{C}(0 \mathrm{~min})$ & Interface temp.: & $200^{\circ} \mathrm{C}$ \\
\hline Total time: & $20 \min$ & TIC scan range: & $35 \sim 260 \mathrm{~m} \mathrm{z}^{-1}$ \\
\hline Carrier gas: & He $(99.999 \%)$ & Threshold: & 100 \\
\hline \multicolumn{4}{|c|}{ Thermal desorber ${ }^{\mathrm{a}}$} \\
\hline Cold trap: & Carbopack $\mathrm{C}+\mathrm{C}$ & & \\
\hline Split ratio: & $1: 20$ & Trap low: & $-10^{\circ} \mathrm{C}$ \\
\hline Split flow: & $5 \mathrm{~mL} \min ^{-1}$ & Trap high: & $320^{\circ} \mathrm{C}$ \\
\hline Trap hold time: & $10 \mathrm{~min}$ & Flow path temp. & $150^{\circ} \mathrm{C}$ \\
\hline \multicolumn{4}{|c|}{ Sampling Tube } \\
\hline Sorbent material: & Tenax TA + Carb & & \\
\hline Desorption flow: & $50 \mathrm{~mL} \mathrm{\operatorname {min } ^ { - 1 }}$ & & \\
\hline Desorption time: & $5 \mathrm{~min}$ & Temp.: & $300{ }^{\circ} \mathrm{C}$ \\
\hline
\end{tabular}

a) TD (UNITY, Markes International, Ltd., UK) 
료와 메탄올로 100 배 희석한 스프레이 용액을 고체 흡착관에 1 마이크로리터 수준으로 주입하여 분석하 였다. 이와 같이 고체흡착관에 열탈착방식으로 분석하 는 기술은 환경시료를 분석하는데 가장 기본적으로 활용할 수 있는 기초적인 분석기술이다. 스프레이 원 제품에 함유된 분석 대상 성분들은 희석하지 않고는 직접 분석이 불가능할 정도로 고농도에 해당한다. 따 라서 이들을 분석하기 위해서는 메탄올과 같은 용매 를 이용하여, 적정 수준(본 연구에서는 100 배) 희석 하여 분석하여야 한다. 그런데 이 때 100 배 희석한 스프레이 시료를 직접 $\mathrm{GC}$ 나 $\mathrm{GC}-\mathrm{MS}$ 에 주입할 경우, 거대한 메탄올 피크에 의해 분석대상 성분들의 상당 부분이 오버랩 또는 소멸하거나 또는 정상적으로 분 석이 이루어져도 리텐션 타임의 왜곡 등으로 정량분 석이 불가하다. 그런데 고체흡착관-열탈착 분석을 적용 할 경우, 고체흡착관에 주입한 용매와 분석대상성분 중에서 용매성분들만 선택적으로 열탈착기의 prepurge 기능을 적용하여 날려 버릴 수 있다. 따라서 용 매에 의한 크로마토그램의 왜곡을 피한 상태로 시료 의 정량분석이 가능하다.

\section{3. 결과 및 고찰}

\section{1. 스프레이 제품에 따른 위험성 조사}

본 연구에서는 시중에 상업적 목적으로 팔고 있는 스프레이 제품을 MS (Mass spectrometer)를 장착한 GC (Gas chromatography) 시스템을 이용하여 분사하 는 과정에서 발생하는 환경오염물질의 배출특성에 대 하여 조사하고자 하였다. 조사대상 물질은 대기 중에 VOC (Volatile organic compounds)로 잘 알려진 벤젠 (Benzene)과 톨루엔(Toluene)을 중심으로 분석하였다.
Table 3. Basic quality assurance in the determination of target VOC (aromatics)

\begin{tabular}{ccccc}
\hline \hline \multirow{2}{*}{ Order } & \multirow{2}{*}{ Parameter } & \multirow{2}{*}{ Unit } & \multicolumn{2}{c}{ Compounds } \\
\cline { 4 - 5 } & & & $\mathrm{B}$ & \multicolumn{1}{c}{$\mathrm{T}$} \\
\hline 1 & Calibration & $\mathrm{r}^{2}$ & $\mathbf{0 . 9 9 6 9}$ & $\mathbf{0 . 9 9 9 8}$ \\
2 & Reproducibility & $\mathrm{RSE}(\%)$ & 1.29 & 3.27 \\
3 & Detection limit & $\mathrm{ppb}(\mathrm{w})$ & $\mathbf{0 . 0 0 1}$ & $\mathbf{0 . 0 0 1}$ \\
\hline
\end{tabular}

각 제품에서 발생특성을 조사하기 위하여, 제품 종류 에 따라 피부에 직접적으로 분사하는 제품 6 종 $(\mathrm{S}$ group), 공기중에 분사하는 제품(A group) 4 종으로 총 10 종의 스프레이 제품을 분석에 이용하였다. 분석 은 액상상태의 스프레이를 실린지를 이용하여 직접 분석하여 결과를 도출하였다(Table 5). 결과 해석에 앞 서 실험 과정의 부주의로 시료가 오염될 가능성을 확 인하기 위하여 공시로(Blank)를 보정하여 오염가능성 을 배제하였다. 결과를 살펴보면, 10 가지 전 제품에 서 벤젠과 톨루엔을 모두 검출하였다. S group의 결과 를 보면, 에어파스 (S-L-1), 데오드란트 (S-L-2), 살충제 -1 (S-L-3), 살충제-2 (S-L-4), 헤어스프레이 (S-L-5), 미 스트 (S-L-6)의 순서로 벤젠의 농도를 평가하면 3.46, $4.23,8.64,7.12,5.78,4.58 \mathrm{ppb}(\mathrm{w})$ (part per billion (weight))로 평균적으로 $5.64 \mathrm{ppb}(\mathrm{w})$ 의 수준으로 검출 되었다. 그리고 A group은 살충제-3 (A-L-1), 살충제4 (A-L-2), 향균스프레이(A-L-3), 방향제(A-L-4)의 순 서로 벤젠의 농도는 $6.75,8.02,8.69,5.75$ 로 평균적으 로 $7.30 \mathrm{ppb}(\mathrm{w})$ 의 수준으로 $\mathrm{S}$ group보다 상대적으로 다소 높은 농도를 보였으며 제품 용도에 따라서는 경 향성을 보이지 않았다. 다음으로 톨루엔의 농도를 보 면, 위에 순서와 마찬가지로 S group은 7.91, 7.56, $9.56,12.8,4.00,9.30 \mathrm{ppb}(\mathrm{w})$ 로 평균적으로 $8.19 \mathrm{ppb}(\mathrm{w})$

Table 4. Preparation of 10 spray samples for analysis of target VOC

\begin{tabular}{ccclccc}
\hline \hline Order & Spray type & Sample code & \multicolumn{1}{c}{ Purpose } & Total volume of product & Sampling date & Analysis date \\
\hline 1 & Skin (LPG) & S-L-1 & Air Pas & $180 \mathrm{~mL}$ & $12-08-15$ & $12-08-16$ \\
2 & $"$ & S-L-2 & Deodorant & $150 \mathrm{~mL}$ & $12-08-15$ & $12-08-16$ \\
3 & $"$ & S-L-3 & Pesticide & $150 \mathrm{~mL}$ & $12-08-15$ & $12-08-16$ \\
4 & $"$ & S-L-4 & Pesticide & $500 \mathrm{~mL}$ & $12-08-15$ & $12-08-16$ \\
5 & $"$ & S-L-5 & Hair Spray & $300 \mathrm{~mL}$ & $12-08-15$ & $12-08-16$ \\
6 & Skin $\left(\mathrm{N}_{2}\right)$ & S-L-6 & Mist & $150 \mathrm{~mL}$ & $12-08-15$ & $12-08-16$ \\
\hline 7 & Air $(\mathrm{LPG})$ & A-L-1 & Pesticide & $500 \mathrm{~mL}$ & $12-08-15$ & $12-08-16$ \\
8 & $"$ & A-L-2 & Pesticide & $500 \mathrm{~mL}$ & $12-08-15$ & $12-08-16$ \\
9 & $"$ & A-L-3 & Antibacteria Spray & $450 \mathrm{~mL}$ & $12-08-15$ & $12-08-16$ \\
10 & $"$ & A-L-4 & Air Freshener & $320 \mathrm{~mL}$ & $12-08-15$ & $12-08-16$ \\
\hline
\end{tabular}


Table 5. Results between benzene and toluene analysis from spray samples

(A) Information for analysis

\begin{tabular}{|c|c|c|c|c|c|}
\hline \multicolumn{3}{|c|}{ Conditions of sample collection } & \multicolumn{3}{|c|}{ Actual spray rate } \\
\hline \multirow{2}{*}{\multicolumn{2}{|c|}{$\begin{array}{l}\text { Injection volume in sampling tube } \\
\text { Sample dilution ratio : }\end{array}$}} & $1 \mu \mathrm{L}$ & Skin or body : & & $\mathrm{mL} / \mathrm{s}$ \\
\hline & & 0.01 & Air : & & $\mathrm{mL} / \mathrm{s}$ \\
\hline \multicolumn{6}{|c|}{ (B) Concentration of VOC in spray product samples } \\
\hline \multirow{3}{*}{ Order } & \multirow{3}{*}{ Sample code } & \multicolumn{4}{|c|}{ Compounds } \\
\hline & & \multicolumn{2}{|c|}{ B } & \multicolumn{2}{|c|}{$\mathrm{T}$} \\
\hline & & (ppb) & $\left(\mathrm{ng} / \mathrm{m}^{3}\right)$ & (ppb) & $\left(\mathrm{ng} / \mathrm{m}^{3}\right)$ \\
\hline 1 & S-L-1 & 3.46 & 20.5 & 7.91 & 46.9 \\
\hline 2 & S-L-2 & 4.23 & 25.1 & 7.56 & 44.8 \\
\hline 3 & S-L-3 & 8.64 & 40.5 & 9.56 & 56.7 \\
\hline 4 & S-L-4 & 7.12 & 42.2 & 12.8 & 75.9 \\
\hline 5 & S-L-5 & 5.78 & 27.1 & 4.00 & 23.7 \\
\hline \multirow[t]{3}{*}{6} & S-L-6 & 4.58 & 34.7 & 9.30 & 55.1 \\
\hline & Mean & 5.64 & 31.7 & 8.52 & 50.5 \\
\hline & $\mathrm{SD}$ & 1.95 & 8.80 & 2.89 & 17.1 \\
\hline 7 & A-L-1 & 6.75 & 6.75 & 7.40 & 24.3 \\
\hline 8 & A-L-2 & 8.02 & 8.02 & 9.50 & 31.1 \\
\hline 9 & A-L-3 & 8.69 & 8.69 & 6.59 & 21.6 \\
\hline \multirow[t]{3}{*}{10} & A-L-4 & 5.75 & 5.75 & 5.25 & 17.2 \\
\hline & Mean & 7.30 & 7.30 & 7.19 & 23.6 \\
\hline & $\mathrm{SD}$ & 1.31 & 1.31 & 1.78 & 5.82 \\
\hline
\end{tabular}

를 나타내었다. 그리고 A group은 7.40, 9.50, 6.59, 5.25 로 평균적으로 $7.19 \mathrm{ppb}(\mathrm{w})$ 을 나타내며 벤젠과 마 찬가지로 제품의 사용목적과 용도에 따른 경향성을 보이지 않았다. 또한, 액상 상태에서 이들 제품들은 보건환경기준의 구강 흡입과 피부 노출에 대한 기준 치에 크게 못 미치는 것을 확인하였다. ${ }^{7}$

일반적으로 스프레이 제품은 고압으로 액상상태로 저장된 휘발성 물질을 $\mathrm{LPG}$ 나 질소 같은 분사제를 이 용하여 분사하는 구조로 이루어져 있다. 이러한 제품 들은 종류에 따라 분무되자 마자 혹은 대기 중에 분 무된 후에 대부분 공기 중으로 기화된다. 따라서, 본 연구에서는 스프레이 제품들이 분무되고 나서 $100 \%$ 수준으로 공기 중에 완전 기화 된다고 가정하였을 때 의 안전성도 함께 평가하고자 하였다. 이를 위하여 실 제 분사속도를 측정한 결과, 피부에 분사하는 제품들 은 평균적으로 $0.47 \mathrm{~mL} / \mathrm{s}$, 공기 중에 분사하는 제품들 은 평균적으로 $0.26 \mathrm{~mL} / \mathrm{s}$ 의 유속을 나타내었다. 측정 된 유속을 이용하여, 실제 스프레이 제품이 10 초간 1 입방미터의 공기 중에 완전 기화되었을 때의 농도

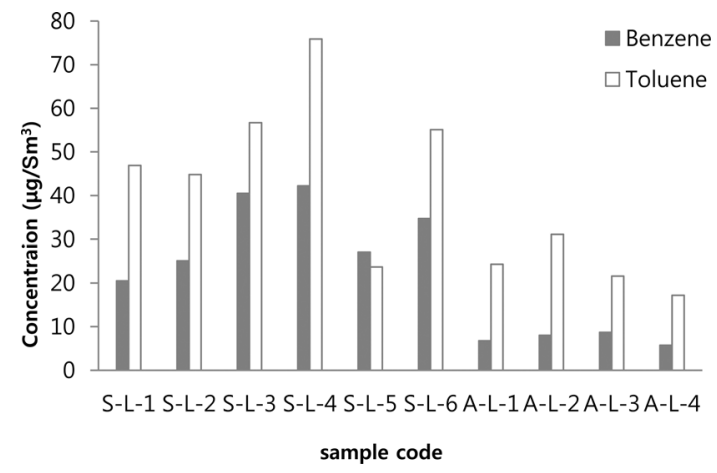

Fig. 3. Comparison of concentration levels of benzene and toluene measured in spray products.

$\left(\mu \mathrm{g} / \mathrm{Sm}^{3}\right)$ 를 도출하였다(Fig. 3). 결과를 보면, 벤젠은 $\mathrm{S}$ group의 경우 $20.5,25.1,40.5,42.227 .1,34.7 \mu \mathrm{g} /$ $\mathrm{Sm}^{3}$ 로 평균적으로 $31.7 \mu \mathrm{g} / \mathrm{m}^{3}$ 의 수준을 나타냈다. A group은 $6.75,8.02,8.69,5.75 \mu \mathrm{g} / \mathrm{Sm}^{3}$ 로 평균적으로 $24.0 \mu \mathrm{g} / \mathrm{Sm}^{3}$ 수준의 농도를 기록하였다. 결과적으로 두 그룹 모두 환경부에서 제시한 대기환경 기준치인 5 
$\mu \mathrm{g} / \mathrm{m}^{3}$ 을 4 배 이상 초과한 수치를 나타냈다. 그러나 실제 일반적인 실내의 방의 크기는 $40 \mathrm{~m}^{3}$ 수준이므로 이를 고려하면 대기환경 기준치에 훨씬 못 미치는 수 준에 달할 수 있다. 그리고 톨루엔의 경우, $\mathrm{S}$ group은 $46.9,44.8,56.7,75.923 .7,55.1 \mu \mathrm{g} / \mathrm{Sm}^{3}$ 로 평균적으로 $50.5 \mu \mathrm{g} / \mathrm{Sm}^{3}$ 를 나타내었다. A group은 평균 23.6으로 상대적으로 $\mathrm{S}$ group보다 낮은 농도값을 나타내었다. 톨루엔의 경우, 인체에 영향을 미치는 최저농도인 100 $\mu \mathrm{g} / \mathrm{m}^{3}$ (8 시간 흡입시) 보다 낮은 값을 나타내지만 환 기가 되지 않는 장소에서 장시간 사용 및 흡입하게 되면 복통, 두통, 구토등의 이상 증상을 야기시킬 수 있다.

\section{2. 선행 연구와의 비교}

본 연구에서 선정한 분사형 제품에 대한 연구는 아 직까지 매우 미미한 실정이다. 따라서 일상생활에서 접촉의 빈도수가 비교적 높은 실내건축자재의 제품들 과의 비교를 통해 휘발성 유기화합물의 노출정도를 파악하고자 하였다. 우선 건축자제 중 실내마감에 사 용되는 벽지(일반 벽지, 천연 벽지), 접착제(요소수지 계 접착제, 무취요소수지계 접착제, 멜라린수지계 접착 제), 페인트(유성 페인트, 수성 페인트) 등과 같은 건 축자재의 단일 물품을 소형챔버를 이용하여 휘발성 유기화합물의 방출량을 측정 결과를 보고하였다. ${ }^{8}$ 그 결과 선정된 제품 중 유성 페인트에서만 벤젠이 검출 되었다. 그러나 톨루엔의 경우 선정한 전 제품인 벽지, 접착제, 페인트에서 $0.0009-0.0225 \mathrm{mg} / \mathrm{m}^{2} \mathrm{~h}$ 가 검출되는 것으로 나타났다. ${ }^{9}$

건축자재를 포함하고 있는 신축공동주택의 경우 내 부에서 발생하는 실내오염물질을 측정함으로서 실질 적으로 인간에게 노출되는 정도를 파악하는것이 가능 하다. 전국 대도시의 36 세대의 신축공동주책의 실내 공기 오염정도를 분석하였다. 그 결과 벤젠의 경우 12 세대에서 권고기준치인 $30 \mathrm{~g} / \mathrm{Sm}^{3}$ 을 초과하는 것으로 나타났으나, 전체 측정세대의 평균 벤젠농도는 19.28 $\mathrm{g} / \mathrm{m}^{3}$ 로 권고기준을 만족하였다. 톨루엔의 경우 32 세 대에서 권고기준을 초과하는것으로 나타났다. 이는 측 정세대의 $88 \%$ 가량이 톨루엔 권고기준을 만족하지 못하는 것으로 전체 측정세대의 평균 농도는 $2,729,89$ $\mathrm{g} / \mathrm{m}^{3}$ 로 권고기준을 약 $270 \%$ 초과하는 것으로 나타났 다. ${ }^{10}$ 위의 결과들과 본 연구에서 선정한 제품에서 발 생하는 벤젠과 톨루엔의 농도 발생 결과를 비교하여 보면 벤젠의 경우 10 개의 분사형 제품의 농도가 건 축자재 및 신축공동주택의 실내공기질 발생 농도보다
더 높은 것으로 나타났다. 톨루엔의 경우 건축재의 단일 품목보다는 발생량이 높게 나타났으나 신축공 동주택의 실내공기질 보다는 낮게 발생하는 것으로 나타났다.

\section{4. 결 론}

본 연구에서는 총 10 종의 스프레이 제품에 대한 벤젠과 톨루엔 중심의 환경오염물질의 배출 위험성에 대하여 알아보고자 하였다. 분석 대상 제품으로는 에 어파스, 데오드란트, 살충제 4 종, 헤어스프레이, 미스 트, 향균 스프레이, 방향제로 선정하였다. 각 제품은 피부에 분무하는 제품 (S group)과 공기중에 분무하는 제품 (A group)으로 분류하여 농도 결과를 평가하였다. 그 결과, 벤젠의 농도는 $\mathrm{S}$ group은 $5.64 \pm 1.95 \mathrm{ppb}(\mathrm{w})$ 수준으로 검출되었고, A group은 7.30 $\pm 1.31 \mathrm{ppb}(\mathrm{w})$ 수준으로 피부에 분사하는 제품보다는 상대적으로 높 은 농도를 나타나내었다. 그리고 톨루엔의 농도는 $\mathrm{S}$ group은 $8.52 \pm 2.89 \mathrm{ppb}(\mathrm{w})$ 수준으로 검출되었고, $\mathrm{A}$ group은 $7.19 \pm 1.78$ 수준으로 살충제 제품들이 다른 제 품에 비해 1.5 2 배 이상 높은 농도를 나타내었다. 하 지만, 전 제품의 농도수준이 $\mathrm{ppb}$ 수준인 것을 감안하 였을 때, 보건환경기준법 노출기준에 크게 못 미치는 것을 확인하였다. 또한, 스프레이 제품을 실제로 분무 하였을 때 공기중의 노출위험성을 평가하기 위하여, 액 상상태로 분무된 스프레이 물질이 공기 중으로 완전 기화된다고 가정하였을 때의 안전성을 평가해 보고자 하였다. 벤젠의 경우, $\mathrm{S}$ group은 평균적으로 $31.7 \pm 8.80$ $\mu \mathrm{g} / \mathrm{Sm}^{3}$, A group은 $24.0 \pm 4.30 \mu \mathrm{g} / \mathrm{Sm}^{3}$ 의 농도값을 보 이며 환경부에서 제시한 대기환경기준치인 $5 \mu \mathrm{g} / \mathrm{Sm}^{3}$ 을 4 배 이상 초과한 수치를 나타내며, 밀폐된 공간에 서의 사용은 인체에 매우 유해한 영향을 미칠 것으 로 사료된다. 톨루엔과 같은 경우에는 $\mathrm{S}$ group은 평 균적으로 $50.5 \pm 17.1 \mu \mathrm{g} / \mathrm{Sm}^{3}$, A group은 23.6 55.83 $\mu \mathrm{g} / \mathrm{Sm}^{3}$ 의 농도값을 보였다. 톨루엔은 공기 중에 100 $\mu \mathrm{g} / \mathrm{Sm}^{3}$ 이상의 농도로 8 시간 이상 신체의 이상증 상을 일으킬 수 있다. 또한, 이러한 스프레이 제품들 은 순간적으로 다량의 양을 분무할 뿐 아니라 일반 적으로 피부와 같은 특정지점이나 방안 같은 밀폐된 공간에서 사용한다. 실제 본 연구에서 제시한 수치 보다 안전성에 위협을 받을 가능성이 높다. 이를 감 안하여, 스프레이 제품 이용시 직접흡입을 피하고, 환기가 잘 되어있는 환경에서의 사용을 권고하여야 할 것으로 사료된다. 


\section{감사의 글}

본 연구는 한국연구재단의 지원으로 이루어졌습니 다(No. 2009-0093848).

\section{참고문헌}

1. M.-H. Lee and K.-H. Kim, Analytical Science and Technology, 25(1), 50-59 (2012).

2. J.-W. Ahn, Y.-H. Kim and K.-H. Kim, Analytical Science and Technology, 25(2), 91-101 (2012).

3. D. Hur, J.-M. Jeon, S.-G. Seo, O.-S. Goo, B.-R. Seo and H.-S. Yoon, Kor. J. Ordor. Engineering., 5(1), 2632 (2006).

4. S.-G. Bang, W.-J. Jo and J.-Y. Shon, SAREK, 18(6),
486-492 (2006).

5. J.-J. Kim, J.-O. Ham, G.-D. Ahn, B.-K. Lee, T.-S. Nam and N.-W. Paik, The Kor. J. of Occuo. Med., 1(2) (1989).

6. G.H. Lee, S. Pandey and K.-H. Kim, Kor. J. Ordor. Engineering., 9(1), 6-15 (2010).

7. Ministry of Environment Notification No. 2010-48 (2010. 07. 14), Republic of Korea.

8. H.-G. Yoo, J.-C. Park and Y.-K. Lee, Architectural Institute of Korea, 21(7), 141-148 (2005).

9. S.-J. Lee, S.-G. Jang, Y.-S. Jo, G.-M. Jung and K.-H. Jung, KOSAE, 21(2), 191-199 (2005).

10. H. Jo, J.-M. Choi and W.-J. Kim, J. Korean, Soc. Uving. Environ. Sys., 13(4), 283-289 (2006). 